\title{
Sylvatic Population of Triatoma infestans from the Bolivian Chaco: from Field Collection to Characterization
}

\author{
François Noireau/*/+, Brigitte Bastrenta**, Silvia Catalá***, Jean-Pierre \\ Dujardin**, Francisco Panzera****, Magdalena Torres***, Ruben Perez****, \\ Cleber Galvão*, José Jurberg*
}

Institut de Recherche pour le Développement (IRD), France, and *Laboratório Nacional e Internacional de Referência em Taxonomia de Triatomíneos, Departamento de Entomologia, Instituto Oswaldo Cruz, Av. Brasil 4365, 21045-900 Rio de Janeiro, RJ, Brasil **IRD, La Paz, Bolivia ***CRILAR, La Rioja, Argentina ****Instituto de Biologia, Seccion Genética Evolutiva, Facultad de Ciencias, Montevideo, Uruguay

A sylvatic Triatoma infestans DM (dark morph) population detected in the Bolivian Chaco was characterized and compared with various domestic ones. The degree of differentiation of DM was clearly within the T. infestans intra-specific level. Nevertheless marked chromatic and morphometric differences as well as differences in antennal pattern, chromosome banding and randomly amplified polymorphic DNA support the hypothesis of a distinct population. Continuous exchange of insects between wild and domestic habitats seems unlikely in the Chaco.

Key words: Triatoma infestans - sylvatic focus - characterization of population

Bolivia is the only country where true sylvatic foci of Triatoma infestans were reported from Andean valleys (Torrico 1946, Bermudez et al. 1993). These sylvatic populations occur always among rock-piles between 2,400 and $2,600 \mathrm{~m}$ altitude. Chromatic pattern, isozyme profiles and DNA sequence analysis are similar between domestic and wild Andean specimens but randomly amplifield polymorphic DNA (RAPD) and morphometrics allow them to be distinguished (Dujardin et al. 1987, 1997, Carlier et al. 1996, Monteiro et al. 1999).

Three years ago, another sylvatic T. infestans population was detected in the Bolivian Chaco (Noireau et al. 1997). Because of chromatic differences with domestic $T$. infestans, they were named dark morphs (DM). Among various natural habitats searched for the presence of $T$. infestans DM, hollow trees were frequently positive (Noireau et al. 2000).

A traditional canonical variate analysis (CVA) was performed using four variables (head mea-

Financial support from the IRD, the UNDP/World Bank/ WHO Special Program for Research and Training in Tropical Diseases (grant 970182), the convention Fiocruz-CNPq/FNS and the ECLAT network.

${ }^{+}$Corresponding author. Fax: +55-21-290.9339

E-mail: noireauf@ioc.fiocruz.br

Received 7 August 2000

Accepted 4 September 2000 sures). Results were illustrated by plotting the individuals on the two canonical variables (CV1 and CV2, Fig. 1) with polygons enclosing each group ("convex hulls"). The canonical factors resulting from their derived shape components clearly isolated the DM specimens from the domestic ones. Their regression on size indicated that these differences were not attributable to allometry, suggesting between DM and domestic T. infestans the existence of true size-independent divergence.

A multivariate analysis of the antennal pattern using six variables corresponding to the number of receptors located on the three distal antennal segments was performed. Two discriminant functions $(\mathrm{P}<0.001)$ allowed to classified accurately $100 \%$ of individuals inside their corresponding groups (Fig. 2). The Mahalonobis distances derived from the analysis were all significant $(\mathrm{P}<0.001)$. The DM population showed an greater similitude with domestic $T$. infestans from Paraguay than Bolivian domestic one. The sylvatic population from Cochabamba presented the more distant antennal pattern with regard to the T. infestans DM.

Crossing experiments were performed between DM and domestic T. infestans from the Chaco. The reciprocal crosses among pairwise combinations were all successful (reproductive compatibility). The chromosome analysis of these hybrids showed normal meiosis with a complete chromosome pairing between homeologous chromosomes.

The cytogenetic analysis confirmed that the DM individuals present the same meiotic process observed in others populations of $T$. infestans. Using 
the C-banding technique, we observed that only three autosomal pairs showed heterochromatic blocks in one or both chromosomal ends. The $T$. infestans specimens originating from the nearest domestic population (Izozog, located $80 \mathrm{~km}$ apart) showed four autosomal pairs with C-positive blocks. From the whole T. infestans previously analyzed, $T$. infestans DM contained low quantity of C-heterochromatin and, consequently, was more similar to insects from Brazil or Uruguay than from Bolivian highland.

Isoenzymatic analyses were applied to distinguish $T$. infestans DM with domestic specimens from the Chaco. The comparison between domestic population and DM did not show no significant allelic differences (23 loci tested). The genetic distance calculed between domestic $T$. infestans and DM was very low (0.037) confirming the pertaining of both populations to the same species.

DM specimens were analyzed by RAPD (3 primers used) and compared with domestic T. infestans from varied origin and sylvatic insects from Andean region. The phylogenetic relationships visualized by a Wagner network showed a geographical separation: Chaco and Andean origin. Inside each branch, sylvatic Andean and DM specimens were detached

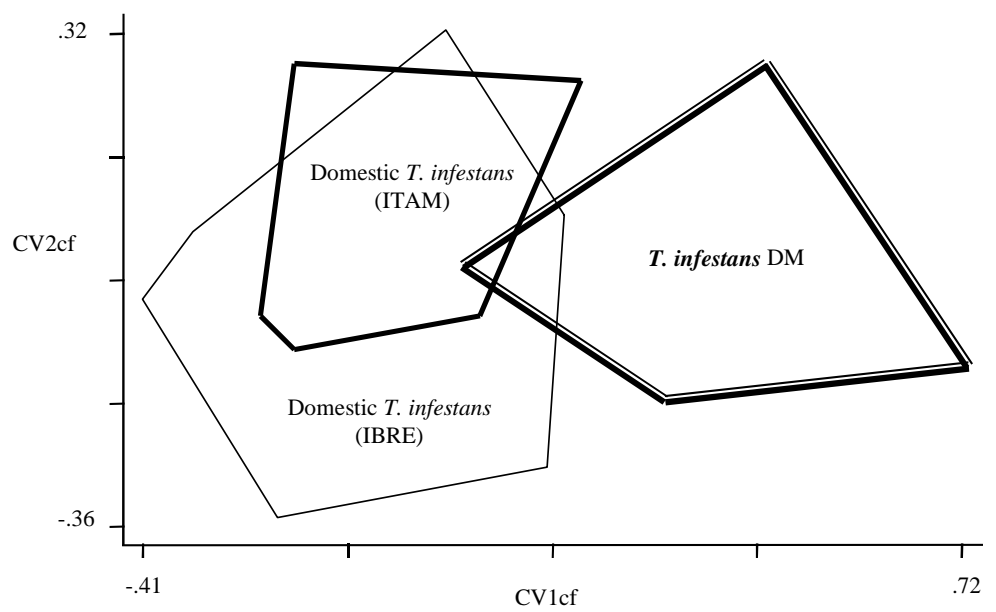

Fig. 1: factorial map based on the measurements of heads of adult dark morph (DM) and domestic Triatoma infestans. CV1 and $\mathrm{CV} 2$ are first and second canonical variants or discriminant factors resulting from their derived shape components. Polygons enclose each group.

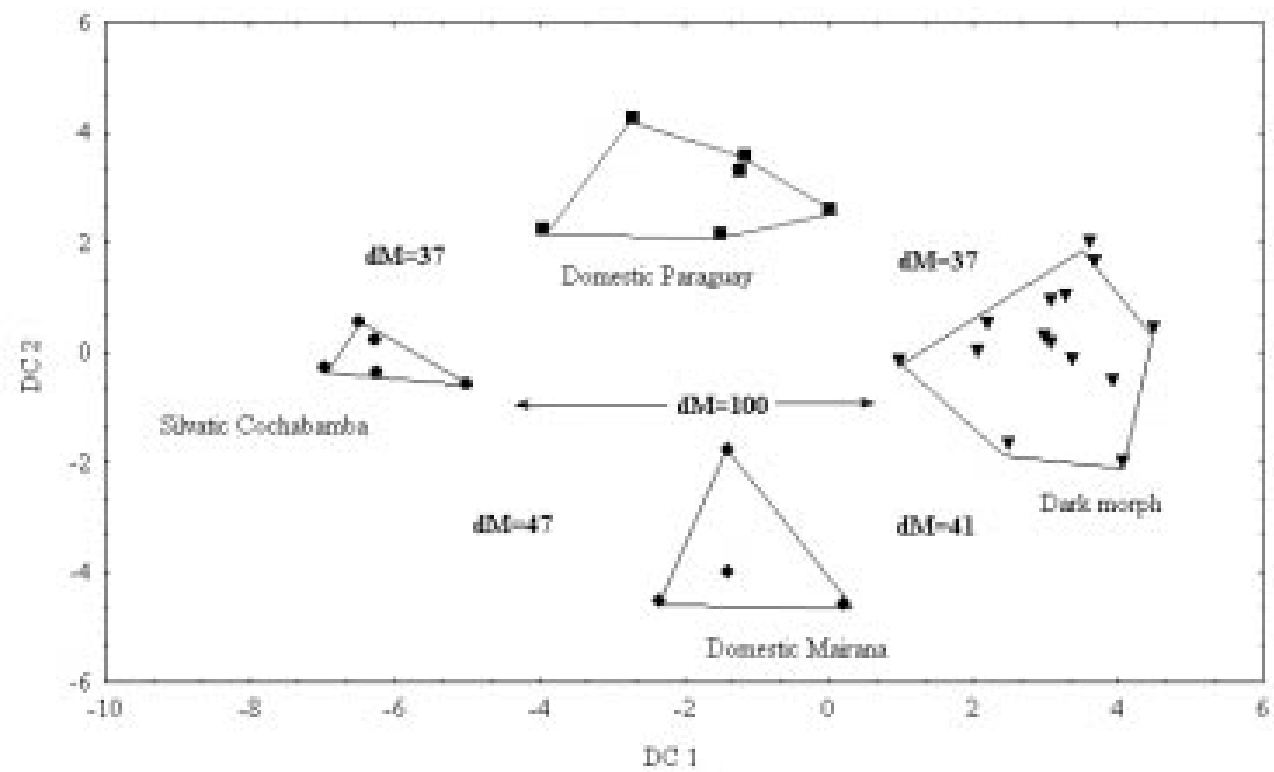

Fig. 2: discriminant analysis of the antennal sensilla pattern from four Triatoma infestans populations. DC1: first discriminant function, DC2: second discriminant function, dM: Mahalanobis distance between centroids 


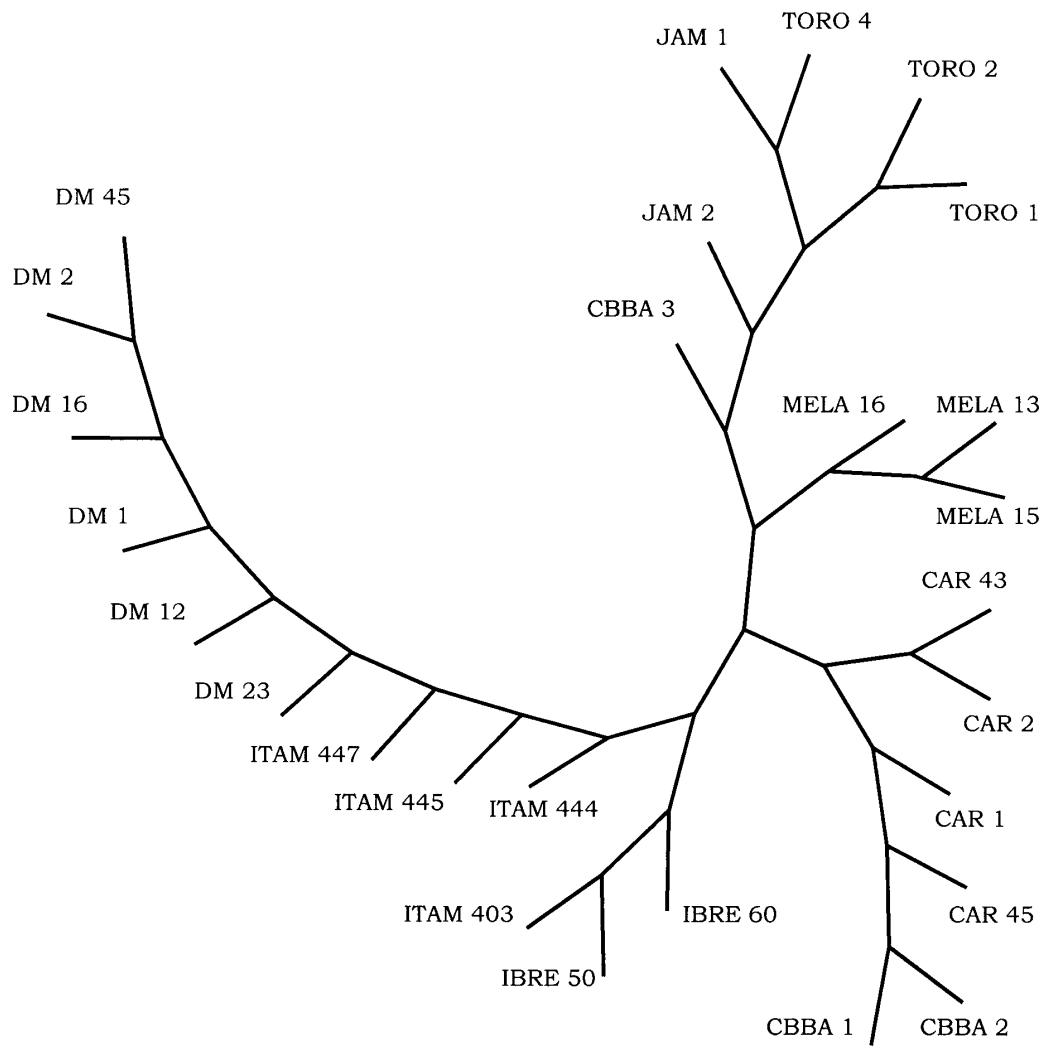

Fig. 3: a minimum-length unrooted Wagner network of 27 Triatominae from different geographical origin randomly amplifield polymorphic DNA (RAPD profiles obtained with A3, A4, A5 primers). Dark morphs: DM 1, DM 2, DM 12, DM 16, DM 23, DM 45; domestic Triatoma infestans from the Chaco: ITAM 403, ITAM 444, ITAM 445, ITAM 447, IBRE 50 and IBRE 60; sylvatic Andean T. infestans: CAR 1, CAR 2, CAR 43, CAR 45, CBBA 1, CBBA 2 and CBBA 3; domestic Andean T. infestans: TORO 1, TORO 3, TORO 4, JAM 1 and JAM 2; T. melanosoma: MELA 13, MELA 15 and MELA 16

from domestic ones (Fig. 3).

Except for research on Andean populations of T. infestans in Bolivia (Torrico 1946, Dujardin et al. 1987, Bermudez et al. 1993), very few studies have considered wild foci. Despite some former reports in other countries (Argentina, Paraguay and Brazil), it was considered that $T$. infestans did not maintain wild foci in these areas because most specimens were found in ecotopes relatively close to human dwellings (Usinger et al. 1966). The inquiry of $T$. infestans wild populations must be again considered in non-Andean areas after the detection of a new true focus in the Bolivian Chaco.

In the Chaco, continuous exchange of insects between wild and domestic habitats seems unlikely because of the marked chromatic and morphometric differences as well as differences in antennal pattern, chromosome banding and RAPD. Nevertheless, as proved by all the techniques, the degree of differentiation of DM was clearly within the $T$. infestans intra-specific level where it would repre- sent a distinct population. At last, the detection of wild T. infestans in the Bolivian Chaco questions about the ancestral population of this species (Carcavallo 1998) when it is classically considered that Andean population represented the original wild focus (Schofield 1988).

\section{REFERENCES}

Bermudez H, Balderrama F, Torrico F 1993. Identification and characterization of wild foci of Triatoma infestans in Central Bolivia. Am J Trop Med Hyg 49 (Suppl.): 371.

Carcavallo RU 1998. Phylogeny of Triatominae. The Triatoma infestans complex. Mem Inst Oswaldo Cruz 93 (Suppl.): 68-70.

Carlier L, Muñoz M, Dujardin JP 1996. RAPD. In CJ Schofield, JP Dujardin, J Jurberg (eds), Proceedings of the Ist International Workshop on Population Genetics and Control of Triatominae, INDRE, Mexico City, p. 81-83.

Dujardin JP, Bermudez H, Schofield CJ 1997. Metric differences between silvatic and domestic Triatoma 
infestans (Heteroptera: Reduviidae) in Bolivia. J Med Entomol 34: 544-551.

Dujardin JP, Tibayrenc M, Venegas E, Maldonado P, Desjeux P, Ayala FJ 1987. Isozyme evidence of lack of speciation between wild and domestic Triatoma infestans (Heteroptera: Reduviidae) in Bolivia. J Med Entomol 24: 40-45.

Monteiro FA, Perez R, Panzera F, Dujardin JP, Galvão C, Rocha D, Noireau F, Schofield CJ, Beard CB 1999. Mitochondrial DNA variation of Triatoma infestans populations and its implication on the specific status of T. melanosoma. Mem Inst Oswaldo Cruz 94: 229-238.

Noireau F, Flores R, Gutierrez T, Abad-Franch F, Flores E, Vargas F 2000. Natural ecotopes of Triatoma infestans dark morph and other sylvatic triatomines in the Bolivian Chaco. Trans R Soc Trop Med Hyg 94: 23-27.

Noireau F, Flores R, Guttierez T, Dujardin JP 1997. Detection of wild dark morphs of Triatoma infestans in the Bolivian Chaco. Mem Inst Oswaldo Cruz 92: 583-584.

Schofield CJ 1988. Biosystematics of the Triatominae. In MW Service, Biosystematics of Haematophagous Insects, Clarendon Press, Oxford, p. 284-312.

Torrico RA 1946. Hallazgo de Eratyrus mucronatus, infestación natural de "vinchucas" de cerro y Eutriatoma sordida en Cochabamba. An Lab Central, Cochabamba, 1: 19-23.

Usinger RL, Wygodzinsky P, Ryckman RE 1966. The biosystematics of Triatominae. Ann Rev Entomol 11: 309-330. 